\title{
DISTÚRBIO ONDULATÓRIO DE LESTE E SEUS IMPACTOS NA CIDADE DE SALVADOR
}

\author{
ANDRÉA HELENA MACHADO DOS SANTOS ${ }^{1}$, MARIA REGINA DA SILVA ARAGÃO ${ }^{2}$, MAGALY \\ DE FATIMA CORREIA ${ }^{2}$, HERÁCLIO ALVES DE ARAUJO ${ }^{3}$, ALEXSANDRA BARBOSA SILVA ${ }^{4}$ \\ ${ }^{1}$ Universidade Estadual do Maranhão, Núcleo Geoambiental, São Luiz, MA, Brasil \\ ${ }^{2}$ Universidade Federal de Campina Grande, Departamento de Ciências Atmosféricas (UFCG/DCA), \\ Campina Grande, PB, Brasil \\ ${ }^{3}$ Instituto do Meio Ambiente e Recursos Hídricos (INEMA), Salvador, BA, Brasil \\ ${ }^{4}$ UniversidadeFederal de Campina Grande, Programa de Pós-graduação em Meteorologia, Campina Grande, PB, Brasil.
}

ahmeteoro@gmail.com,regina@dca.ufcg.edu.br,magaly@dca.ufcg.edu.br, heraclio.araujo@inga.ba.gov.br, alexsandrabs@yahoo.com.br

Recebido Junho de 2010 - Aceito Dezembro de 2011

\begin{abstract}
RESUMO
Um evento extremo de chuva registrado na cidade de Salvador, Bahia, é investigado neste trabalho. Dados observacionais de superfície e altitude, dados em pontos de grade, imagens de satélite meteorológico e informações de desastres fornecidas pela Defesa Civil de Salvador (CODESAL) foram utilizados na análise. No período entre a meia noite e 3 horas da madrugada do dia 12 de junho de 2006, a precipitação acumulada foi de $51 \mathrm{~mm}$. Um número elevado de ocorrências foi registrado pela CODESAL, notadamente deslizamentos de encosta. Ventos fracos em toda a troposfera e energia potencial convectiva disponível máxima de $3.233 \mathrm{~J} \mathrm{~kg}^{-1}$ foram diagnosticados em Salvador no dia 11 de junho, quinze horas antes do período de chuva forte. Áreas de convecção profunda caracterizaram esse evento provocado por uma onda que chegou à costa leste do Nordeste do Brasil, após se propagar para oeste sobre o Atlântico Sul com velocidade de fase estimada de $10 \mathrm{~m} \mathrm{~s}^{-1}$, conforme evidenciado no campo da componente meridional do vento no nível de $700 \mathrm{hPa}$ e em imagens de satélite meteorológico. Palavras-chave: evento extremo, área urbana, energia potencial convectiva disponível, Nordeste do Brasil
\end{abstract}

ABSTRACT: WAVELIKE EASTERLY DISTURBANCE AND ITS IMPACTS ON SALVADOR CITY: An extreme rainfall event registered in the city of Salvador, Bahia, is investigated in this work. Observational surface and upper air data, gridpoint data, meteorological satellite images and disasters information provided by the Civil Defense of Salvador (CODESAL) were used in the analysis. During the period from midnight to 3 A.M. on 12 June $200651 \mathrm{~mm}$ accumulated rainfall was registered. A high number of disasters were registered by CODESAL, particularly landslides. Weak winds throughout the troposphere and maximum convective available potential energy of $3,233 \mathrm{~J} \mathrm{~kg}^{-1}$ were identified in Salvador on June 11th, fifteen hours before the heavy rainfall. Areas of deep convection characterized this event, favored by a wave that reached the eastern coast of Northeast Brazil after moving westward over the South Atlantic with an estimated phase speed of $10 \mathrm{~m} \mathrm{~s}^{-1}$, as seen on the meridional wind component field at the $700 \mathrm{hPa}$ level and on meteorological satellite images.

Keywords: extreme event, urban area, convective available potential energy, Northeast Brazil

\section{INTRODUÇÃO}

Fenômenos da natureza como grandes secas, frios excessivos, tsunamis, erupções vulcânicas, têm sido responsáveis pelo colapso de civilizações e extermínio em massa de seres vivos, desde os tempos pré-históricos. Basicamente, as grandes calamidades naturais são de duas origens: meteorológica e geológica (vulcanismo, terremotos e maremotos). No primeiro caso estariam os excessos de chuvas responsáveis por enchentes, deslizamentos de encostas e alagamentos; as secas muito prolongadas que aniquilam colheitas, desencadeando surtos de fome e miséria; extremos de frio ou de calor e catástrofes 
produzidas pelos ventos intensos associados a tornados e ciclones tropicais (Conti, 1998).

Tratando-se dos desastres naturais ocasionados por chuvas, essas se tornam particularmente destrutivas. Quando precipitam em grande quantidade e num período de tempo muito curto, principalmente em centros urbanos. No Nordeste do Brasil (NEB), onde a variabilidade espacial da chuva é muito grande (Lima, 1991), a faixa litorânea do Rio Grande do Norte ao sul da Bahia, que se caracteriza por um regime de chuvas satisfatório em termos de regularidade e volume (Magalhães et al., 1987), merece atenção especial. Segundo o Instituto Brasileiro de Geografia e Estatísticas (IBGE), aproximadamente $40 \%$ da população nordestina vive nessa área. De acordo com Lima (1991), a costa leste, se comparada com outras áreas do NEB, é mais complexa em termos dos mecanismos dinâmicos que favorecem a atividade pluviométrica. Isso se explica, em parte, pela diversidade de sistemas da circulação atmosférica, em várias escalas, que atuam nessa área, podendo-se destacar, dentre outros, os Distúrbios Ondulatórios de Leste (DOLs), que ocasionalmente provocam chuvas fortes.

Os DOLs são distúrbios que se propagam para oeste na área dos ventos alísios, apresentando configurações ondulatórias nos campos de vento e pressão (Berry et al., 1945). De acordo com Hastenrath (1988), o DOL é o sistema mais comum do regime dos ventos alísios, sendo mais frequente no lado equatorial do cinturão subtropical e mais intenso na média troposfera. Esse sistema se desloca sobre o Oceano Atlântico até o litoral e a Zona da Mata nordestina. Os DOLs são de extrema importância por provocarem alterações significativas nas condições sinóticas, principalmente na componente meridional do vento, tendo como consequência uma umidificação da camada, aumento de nebulosidade e precipitação (Coutinho e Fish, 2007; Paiva Neto, 2003; Mota, 1997).

Os centros urbanos apresentam fatores que agravam as consequências das chuvas fortes, tais como impermeabilização maciça do solo, insuficiência de infraestrutura, desmatamento e ocupação desordenada do solo, entre outros. Na cidade de Salvador que, de acordo com o IBGE, é a terceira capital do Brasil em número de habitantes, as chuvas fortes causam transtornos graves. Na história recente da cidade o ano de 2006 se destaca pelo número elevado de eventos de chuva intensa (Barreto et al., 2008). No período de outono/inverno desse ano as concentrações de grande volume de chuva em curtos períodos de tempo favoreceram a saturação do solo. Os registros da Defesa Civil local atestam a gravidade dos problemas enfrentados pela cidade, particularmente no mês de junho (CODESAL, 2006), quando Salvador foi declarada em Situação de Emergência (reconhecimento legal pelo poder público de situação anormal, provocada por desastres, causando danos à comunidade afetada) nos dias 12,13 e 14 .
Nesse contexto, neste trabalho o objetivo é investigar as condições atmosféricas e caracterizar os impactos sofridos pela cidade de Salvador no dia 12 de junho de 2006. O número elevado de deslizamentos de terra, desabamento de imóveis e muros, rompimento da fiação elétrica, árvores caídas, alagamentos e obstrução de ruas registrado pela Defesa Civil local motivou a realização deste estudo.

\section{MATERIAL E MÉTODOS}

O evento de chuva forte analisado neste trabalho foi selecionado considerando os totais diários de precipitação observados em quatro estações meteorológicas da cidade, a saber: estação convencional do Instituto Nacional de Meteorologia (INMET); estação pertencente a antiga Empresa de Limpeza Urbana de Salvador-LIMPURB; estação da Battre-Bahia Transferência e Tratamento de Resíduos S.A., e estação automática operada pelo Instituto de Gestão das Águas e Clima (INGÁ), atualmente o Instituto do Meio Ambiente e Recursos Hídricos (INEMA). A análise dos totais diários de chuva permitiu identificar os dias com valor acima de $50 \mathrm{~mm}$, equivalente ao nonagésimo sétimo percentil da série histórica do INMET (Barreto et al., 2008). Os transtornos ocasionados pelas chuvas, documentados em Santos (2008), também foram considerados. Dessa forma, o evento do dia 12 de junho de 2006 foi selecionado para análise.

O diagnóstico da circulação atmosférica foi realizado através de dados de pressão reduzida ao nível médio do mar $(\mathrm{hPa})$, componente zonal $(\mathrm{u})$ e meridional $(\mathrm{v})$ do vento $\left(\mathrm{m} \mathrm{s}^{-1}\right)$ e movimento vertical em coordenadas de pressão $\left(\mathrm{hPa} \mathrm{s}^{-1}\right)$ obtidos das reanálises dos National Centers for Environmental Predictions/National Center for Atmospheric Research (NCEP/ NCAR) nos níveis isobáricos padrões, com espaçamento de grade de $2,5^{\circ} \times 2,5^{\circ}$, para os horários das $0000,0600,1200$ e 1800 UTC. $\mathrm{O}$ acompanhamento visual do desenvolvimento de sistemas meteorológicos também foi realizado através de imagens dos satélites meteorológicos METEOSAT e GOES-E no canal do infravermelho térmico, em um total de oito em vinte e quatro horas, correspondentes às horas inteiras múltiplas de três horas.

Dados horários de superfície registrados pela estação automática do INEMA possibilitaram analisar a variabilidade do vento e da precipitação acumulada. A estrutura termodinâmica e do vento na vertical de Salvador foi diagnosticada através de dados de sondagens de ar superior realizadas às 1200 UTC na estação de altitude do INMET, obtidos no portal da Universidade de Wyoming (www.weather.uwyo.edu/upperair/sounding.html). As condições de estabilidade da atmosfera foram investigadas através de perfis verticais da temperatura potencial $(\theta)$, temperatura potencial equivalente $\left(\theta_{\mathrm{e}}\right)$ e temperatura potencial equivalente de saturação $\left(\theta_{\text {es }}\right)$, calculadas segundo as equações 
propostas por Bolton (1980). O cisalhamento vertical do vento foi ilustrado com a utilização de hodógrafas.

Amplas evidências indicam que o desenvolvimento de sistemas convectivos profundos (convecção isolada ou organizada em mesoescala) tem forte relação com a CAPE - Energia Potencial Disponível para Convecção (Bluestein, 1993; Domingues et al., 2004). Neste trabalho, a obtenção desta medida do grau de atividade convectiva foi baseada na metodologia de Correia (1989), sendo denominada de Energia Potencial Convectiva Disponível Máxima $\left(\mathrm{CAPE}_{\mathrm{MÁX}}\right)$. A necessidade de obter o valor máximo da CAPE surgiu em função do horário da sondagem, realizada às 1200 UTC, pois a atividade convectiva normalmente aumenta no decorrer do dia em áreas continentais. A partir do valor máximo da temperatura do bulbo úmido em superfície, foi encontrado o valor correspondente da temperatura potencial máxima do bulbo úmido através de diagrama termodinâmico e, em seguida, a temperatura da parcela.

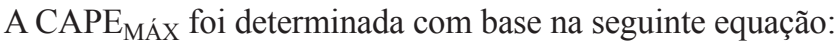

$$
\text { CAPE }_{M A ́ X}=g \int_{N C L}^{N E} \frac{T_{v p}-T_{v a}}{T_{v a}}
$$

na qual: $\mathrm{g}$ é a aceleração da gravidade $\left(\mathrm{m} \mathrm{s}^{-2}\right) ; \mathrm{T}_{\mathrm{va}}=\left(\mathrm{T}_{\mathrm{a}}+0,61 \mathrm{q}\right)$ é a temperatura virtual do ambiente $\left({ }^{\circ} \mathrm{C}\right) ; \mathrm{T}_{\mathrm{vp}}=\left(\mathrm{T}_{\mathrm{p}}+0,61 \mathrm{q}\right)$ é a temperatura virtual da parcela $\left({ }^{\circ} \mathrm{C}\right) ; \mathrm{T}_{\mathrm{a}}$ é a temperatura do ambiente $\left({ }^{\circ} \mathrm{C}\right)$; q é a umidade específica $\left(\mathrm{g} \mathrm{kg}^{-1}\right) ; \mathrm{T}_{\mathrm{p}}$ é a temperatura da parcela obtida através do diagrama termodinâmico com base no valor mais alto da temperatura do bulbo úmido $\left(\mathrm{T}_{\mathrm{w}}\right)$, (determinado com base nos dados horários de superfície da estação automática do INEMA); NE é o nível de equilíbrio (nível no qual $T_{a}=T_{p}$ ); NCL é o nível de convecção por levantamento.

\section{RESULTADOS E DISCUSSÕES}

\subsection{Análise das condições atmosféricas em superfície}

O dia 12 de junho de 2006 se destaca pela intensidade e volume das chuvas observadas na cidade de Salvador. A Figura 1 ilustra o valor médio dos totais diários de precipitação das quatro estações e os totais diários da estação automática do INEMA. É possível observar que chove em todos os dias do mês, com exceção de $01,02,27$ e 28 . No dia 12 as quatro estações registram totais pluviométricos acima de $80 \mathrm{~mm}$, conforme indica a média na Figura 1. A estação do INMET, em particular, registra $95 \mathrm{~mm}$ de chuva, valor que representa $40 \%$ da normal climatológica do mês, que é de 243,7 mm (Ramos et al., 2009). Vale ressaltar o grande volume de chuva no mês de junho de 2006, que apresenta um excedente de $158 \mathrm{~mm}$, já que o total mensal é de 401,4 mm. A Figura 2, que ilustra a variação horária da precipitação acumulada, mostra que a chuva começa fraca às
1100 UTC do dia 11 de junho. Não há mudança significativa na intensidade até a madrugada do dia 12, quando começa a chuva forte. Num intervalo de três horas (0300 a 0600 UTC), a estação automática registra um total de $51 \mathrm{~mm}$, valor que representa $21 \%$ da normal climatológica do mês de junho.

A variabilidade do vento à superfície é ilustrada na Figura 3 através das médias diárias das componentes u e v. É possível observar que o vento é fraco no decorrer do mês; há um pequeno aumento na intensidade no dia 8 , que se mantem até o dia 10. Nesses três dias, e no dia 11, o vento é de sul-sudeste. No dia 12 (dia do evento de chuva forte), o vento é do quadrante sudoeste.

\subsection{Análise da estabilidade e do vento em altitude}

As condições de estabilidade da atmosfera nos dias 11 e 12 de junho de 2006, em Salvador, são avaliadas com base nos perfis verticais da temperatura potencial $\left(\theta_{\mathrm{e}}\right)$, temperatura

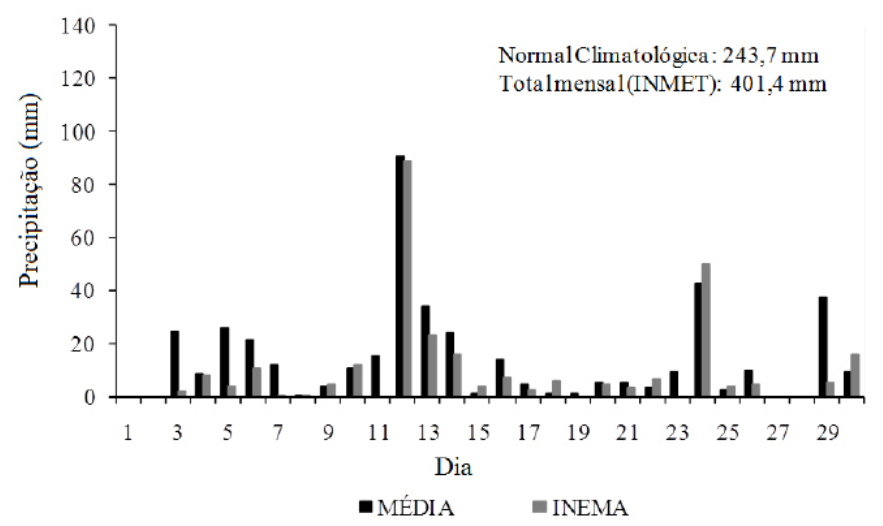

Figura 1 - Média diária dos totais de precipitação ( $\mathrm{mm})$ das quatro estações meteorológicas (preto) e totais diários de precipitação (mm) da estação automática do INEMA (cinza) para o mês de junho de 2006 em Salvador.

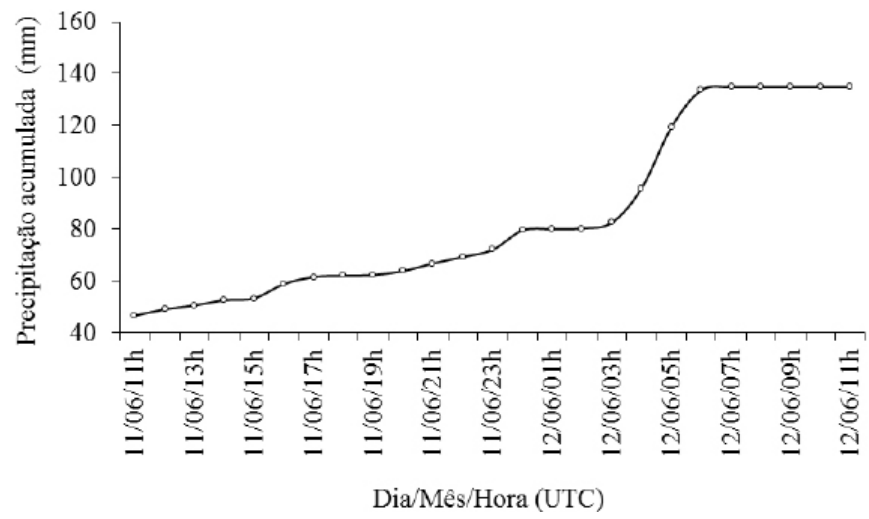

Figura 2 - Precipitação horária acumulada (mm) na estação automática do INEMA em Salvador, no período das 1100 UTC do dia 11 às 1100 UTC do dia 12 de junho de 2006. 


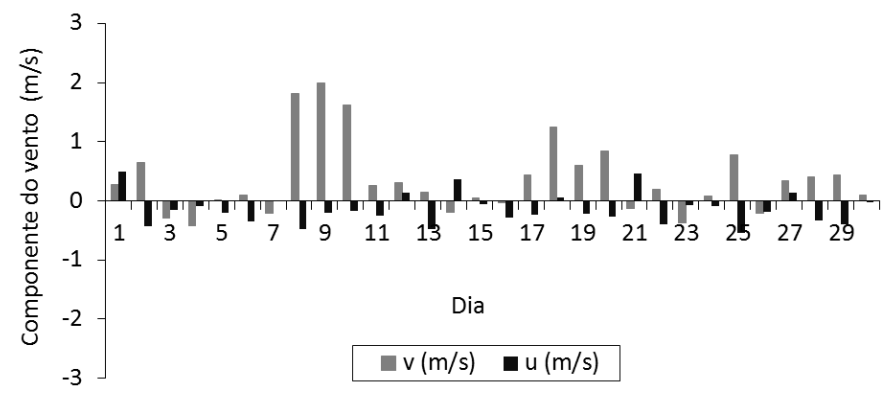

Figura 3 -Componente zonal (u) e meridional (v) média diária do vento em superfície $\left(\mathrm{m} \mathrm{s}^{-1}\right)$ registrado na estação automática do INEMA em Salvador no mês de junho de 2006.

potencial equivalente $\left(\theta_{\mathrm{e}}\right)$ e temperatura potencial equivalente de saturação $\left(\theta_{\mathrm{es}}\right)$ obtidos das sondagens de ar superior realizadas às 1200 UTC (Figura 4). No dia anterior ao evento de chuva forte (11 de junho), a atmosfera se encontra relativamente úmida entre a superfície e $760 \mathrm{hPa}$, aproximadamente (Figura 4a). Logo acima de $760 \mathrm{hPa}$, observa-se o afastamento acentuado entre as curvas de $\theta_{\mathrm{e}}$ e $\theta_{\mathrm{es}}$, caracterizando a base de uma camada de inversão térmica, na qual há forte secagem na atmosfera. Essa estrutura é típica de situações em que a camada de inversão térmica se desenvolve devido à subsidência associada à Alta Subtropical do Atlântico Sul (ASAS). Os perfis de $\theta_{\mathrm{e}}$ e $\theta_{\mathrm{es}}$, praticamente sem variação entre 760 e $900 \mathrm{hPa}$, indicam uma atmosfera bastante misturada. A atmosfera é condicionalmente instável na camada entre $900 \mathrm{hPa}$ e a superfície, caracterizada pela diminuição de $\theta_{\mathrm{es}}$ com a altura. Nos perfis verticais do dia 12 , a proximidade entre as curvas de $\theta_{\mathrm{e}}$ e $\theta_{\mathrm{es}}$ indica que a atmosfera tem alto teor de umidade até níveis mais elevados (Figura 4b). A CAPE ${ }_{\text {MÁx }}$ para esse dia é de $2.977 \mathrm{~J} \mathrm{~kg}^{-1}$, enquanto que no dia anterior é de $3.233 \mathrm{~J} \mathrm{~kg}^{-1}$, valores esses que indicam alto grau de instabilidade convectiva e, portanto, condições favoráveis para o desenvolvimento de convecção profunda. Vale ressaltar que inversões térmicas de subsidência impedem o desenvolvimento vertical das nuvens. Uma condição necessária para que a energia convectiva seja liberada é a atuação de algum mecanismo dinâmico de meso ou grande escala que enfraqueça ou destrua a camada de inversão. As hodógrafas do vento também são ilustradas na Figura 4. Na baixa e média
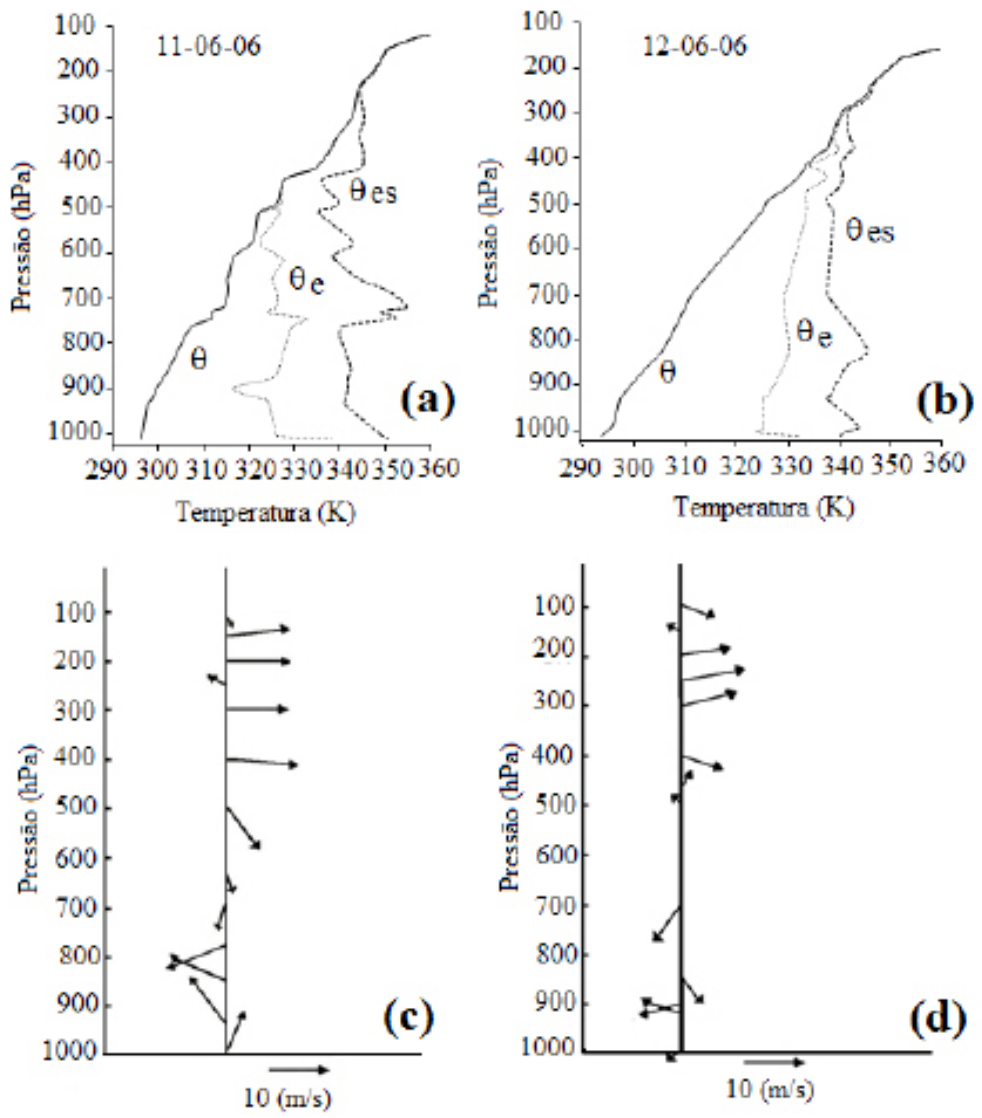

Figura 4 - Perfis verticais da temperatura potencial $(\theta)$, temperatura potencial equivalente $\left(\theta_{\mathrm{e}}\right)$ e temperatura potencial equivalente de saturação $\left(\theta_{\mathrm{es}}\right)(\mathrm{a}, \mathrm{b})$, e hodógrafas do vento $\left(\mathrm{m} \mathrm{s}^{-1}\right)(\mathrm{c}, \mathrm{d})$ obtidas de sondagens de ar superior realizadas em Salvador às 1200 UTC dos dias: $(\mathrm{a}, \mathrm{c}) 11 \mathrm{e}(\mathrm{b}, \mathrm{d})$ 12 de junho de 2006.

Fonte dos dados: www.weather.uwyo.edu/upperair/sounding.html. 
troposfera a direção do vento é bastante variável, alternando entre os quatro quadrantes da rosa dos ventos, principalmente no dia 11 (Figura 4c). As velocidades são baixas; o valor mais elevado é registrado em $400 \mathrm{hPa}$ no dia 11: $12,3 \mathrm{~m} \mathrm{~s}^{-1}$.

\subsection{Análise do ambiente sinótico}

O desenvolvimento do evento extremo de chuva pode ser acompanhado através das imagens do satélite GOES-E obtidas em intervalos de 3 horas (Figura 5). É possível observar, já às 0000 UTC do dia 11 de junho, a formação das primeiras células de convecção profunda próximo à costa leste do Nordeste (Figura 5a). O desenvolvimento prossegue ao longo do dia, aumentando consideravelmente a área coberta por nuvens (Figuras 5b e 5c). No dia 12 a convecção se apresenta organizada em mesoescala e cobre a costa leste do Nordeste e área oceânica adjacente (Figuras 5d-5h). Outras áreas de nebulosidade são observadas no noroeste-norte da América do Sul, com destaque para a banda de convecção profunda ao longo do litoral norte do Nordeste às 2100 UTC do dia 11 e 0000 UTC do dia 12 (Figuras 5 c e 5d), numa configuração típica de linha de instabilidade. É possível notar também na sequência de imagens a presença de uma banda de nebulosidade frontal, que penetra no Sul-Sudeste e se desloca para o oceano. A análise de imagens de satélite de dias anteriores (não mostradas) evidencia células de nuvens com deslocamento de leste para oeste sobre o oceano Atlântico Sul, culminando na nebulosidade discutida anteriormente.

A propagação para oeste também foi investigada através de seções tempo-longitude da componente meridional do vento ao longo de $13^{\circ} \mathrm{S}$, latitude de Salvador. Essa representação foi usada para vários níveis isobáricos padrões. Segundo Laurent et al. (1989), o DOL pode ser detectado em vários níveis isobáricos padrões, mas geralmente se utiliza o nível de $500 \mathrm{hPa}$ como indicador do evento. Dentre as seções tempo-longitude analisadas, a inclinação das áreas positivas (componente de sul) e negativas (componente de norte) possibilitou detectar propagação para oeste apenas no nível de $700 \mathrm{hPa}$ (Figura 6). Estudos realizados sobre os DOLs que se propagam sobre o Atlântico Sul, diagnosticaram que esses sistemas são mais intensos no nível de 700 hPa (Mota, 1997; Paiva Neto, 2003). No dia 11 de junho, próximo de $38^{\circ} \mathrm{W}$ (longitude de Salvador), a componente meridional que era de sul passa a ser de norte, o que sugere a estrutura de um DOL segundo o modelo conceitual proposto por Hall (1989). A atuação da componente de norte coincide com o aumento da área coberta e da profundidade das nuvens ilustradas nas imagens de satélite (Figura 5), em concordância com o estudo de composição de Mota (1997), que encontrou precipitação mais intensa em Natal-RN com componente de norte máxima. Através da Figura 6 também foi possível estimar a velocidade de fase do sistema em $10 \mathrm{~m} \mathrm{~s}^{-1}$, valor semelhante àquele obtido por Mota (1997) e Paiva Neto (2003).

A estrutura do DOL, representada por um cavado invertido situado no leste do Nordeste e área oceânica adjacente, é visualizada no campo da pressão ao nível médio do mar para as 0000 UTC do dia 12 de junho (Figura 7), três horas antes do início do período de chuva intensa em Salvador. Nesse mapa, a ASAS está centrada em torno de $\left(27^{\circ} \mathrm{S}, 17^{\circ} \mathrm{W}\right)$; outra área de alta pressão é observada sobre o sudeste da América do Sul, na
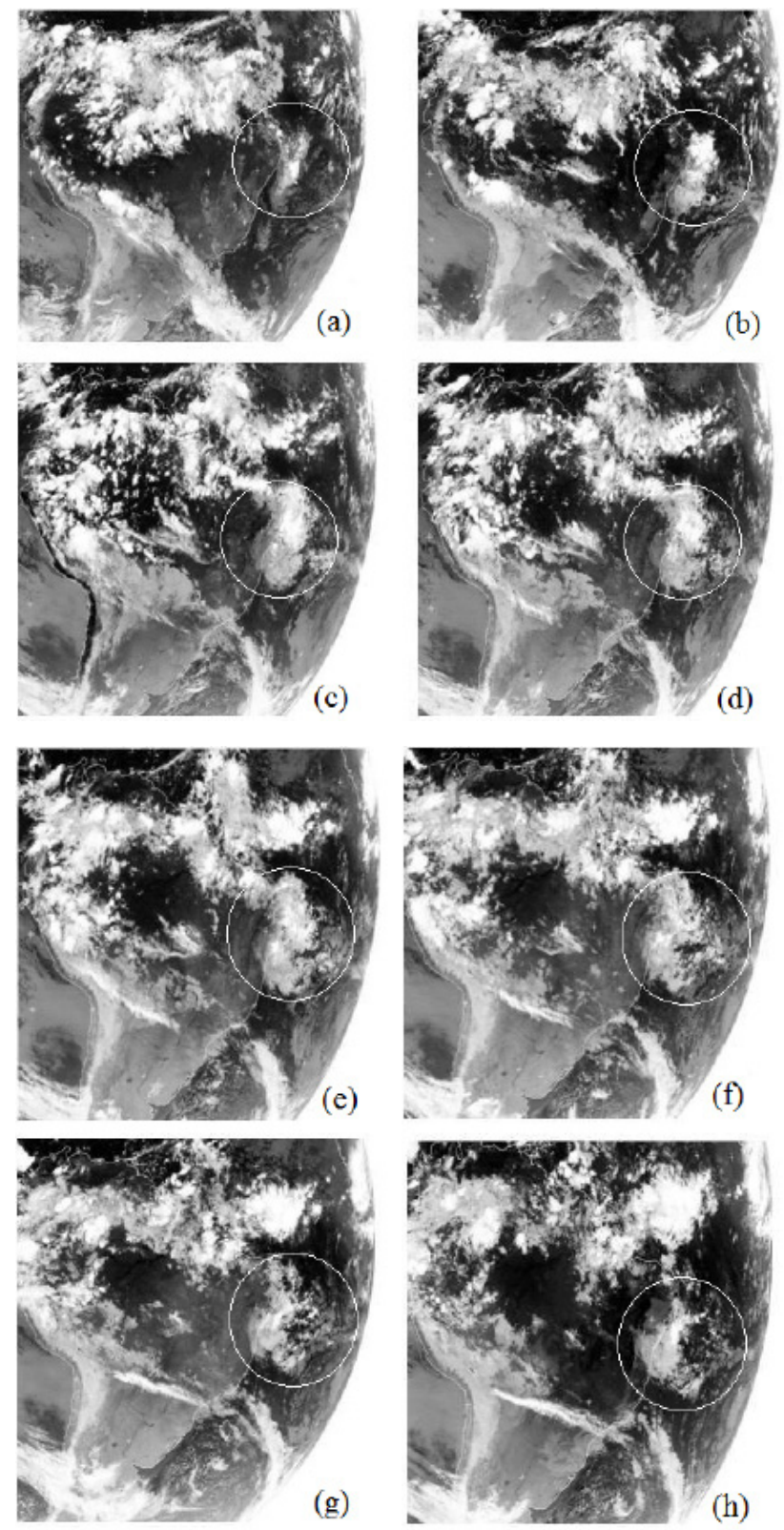

Figura 5 - Imagens do satélite meteorológico GOES-E na banda do infravermelho térmico para o dia 11 de junho de 2006 às 0000 UTC (a), 1200 UTC (b), 2100 UTC (c), e dia 12 de junho às 0000 UTC (d), 0300 UTC (e), 0600 UTC (f), 0900 UTC (g) e 1200 UTC (h). A circunferência branca indica a nebulosidade associada ao DOL. 


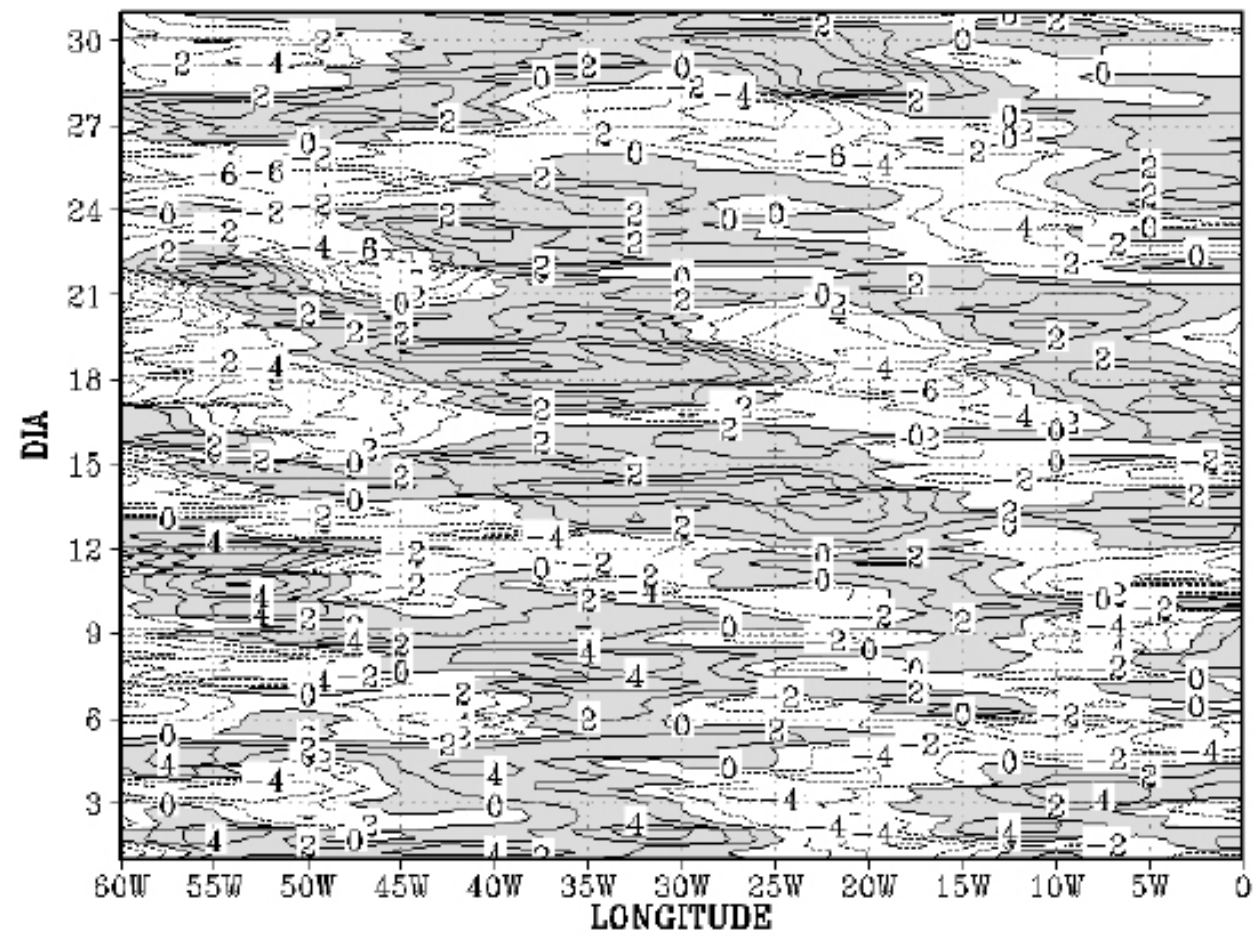

Figura 6 - Seção tempo-longitude da componente meridional do vento no nível de $700 \mathrm{hPa}$ para o mês de junho de 2006 ao longo de $13^{\circ} \mathrm{S}$, latitude de Salvador. O intervalo de análise é de $2 \mathrm{~ms}^{-1}$. As áreas sombreadas assinalam componente de sul.

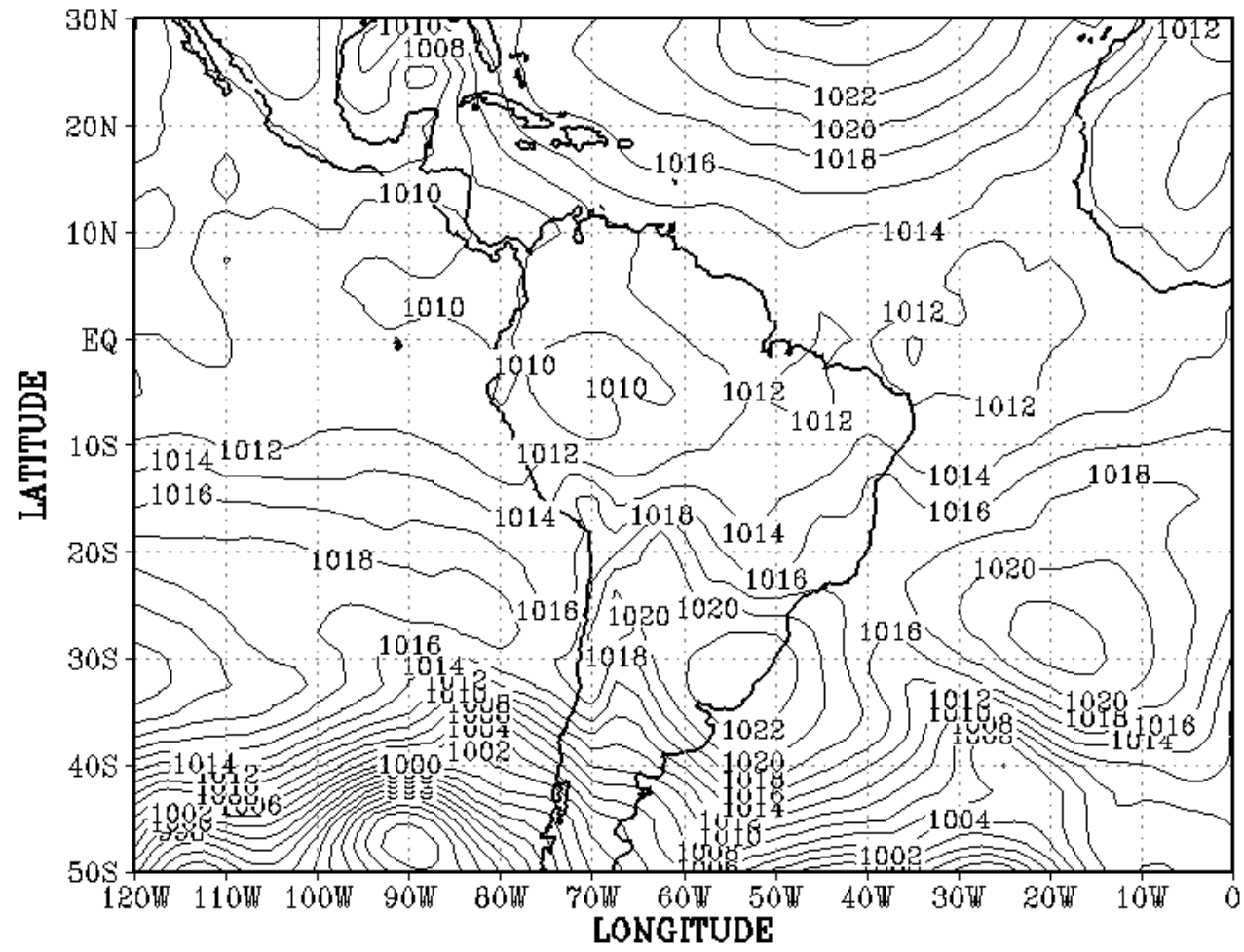

Figura 7 - Pressão reduzida ao nível médio do mar às 0000 UTC do dia 12 de junho de 2006. O intervalo de análise é de 2 hPa. 
retaguarda da frente fria identificada na imagem de satélite para o mesmo dia e horário (Figura 5d).

O cavado na área dos ventos alísios se estende na baixa troposfera, uma característica evidenciada no campo do vento dos níveis de 850 e 700 hPa (Figuras 8a e 8b).O sinal desse sistema no campo da vorticidade relativa é o centro ciclônico visto na mesma área nas Figuras 9a e 9b. Sua magnitude é o dobro daquela encontrada no estudo de caso do DOL de junho de 1995 realizado por Paiva Neto (2003). No campo do vento no nível de 500 hPa (Figura 8c), o norte da área litorânea leste do Nordeste é influenciado por um ponto neutro; circulações anticiclônicas (ciclônicas) são vistas a leste e a oeste (ao norte e ao sul) do mesmo. No nível de $200 \mathrm{hPa}$, há um centro anticiclônico na área do ponto neutro (Figura 8d) e vorticidade anticiclônica (Figura 9d). Essa estrutura vertical na área litorânea indica uma condição de ascendência na atmosfera,
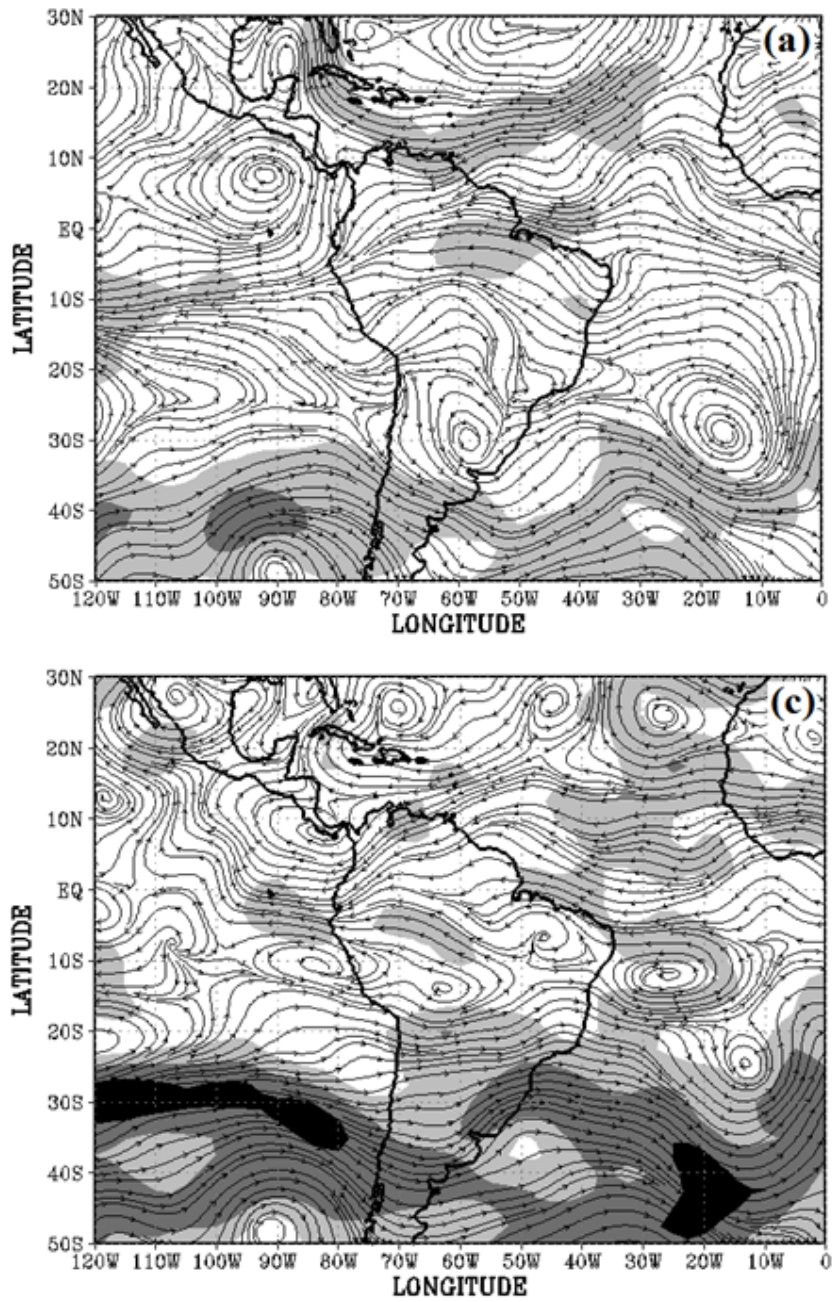

favorecida por convergência (divergência) na baixa (alta) troposfera. Nota-se também em latitudes subtropicais o cavado associado à nebulosidade frontal identificada nas imagens de satélite (Figura 5). Esse cavado se estende ao sul de $20^{\circ} \mathrm{S}$, a leste do continente, nos níveis de 925 e $850 \mathrm{hPa}$ (Figuras $8 \mathrm{a}$ e 8 b) e atinge latitudes mais baixas no nível de $500 \mathrm{hPa}$ (Figura $8 \mathrm{c}$ ). Ainda nesses níveis é observado o núcleo de vorticidade ciclônica associado ao cavado de latitudes médias, centrado em torno de $\left(35^{\circ} \mathrm{S}, 30^{\circ} \mathrm{W}\right)$.

A condição de ascendência na área litorânea foi investigada para os quatro horários sinóticos do dia 12 de junho através de seções pressão-longitude do movimento vertical em coordenadas de pressão, ao longo de $13^{\circ} \mathrm{S}$, latitude de Salvador (Figura 10). É possível observar nas proximidades de $38^{\circ} \mathrm{W}$ (longitude de Salvador), uma área de movimento ascendente às 0000 UTC (Figura 10a). Essa mesma área apresenta um núcleo
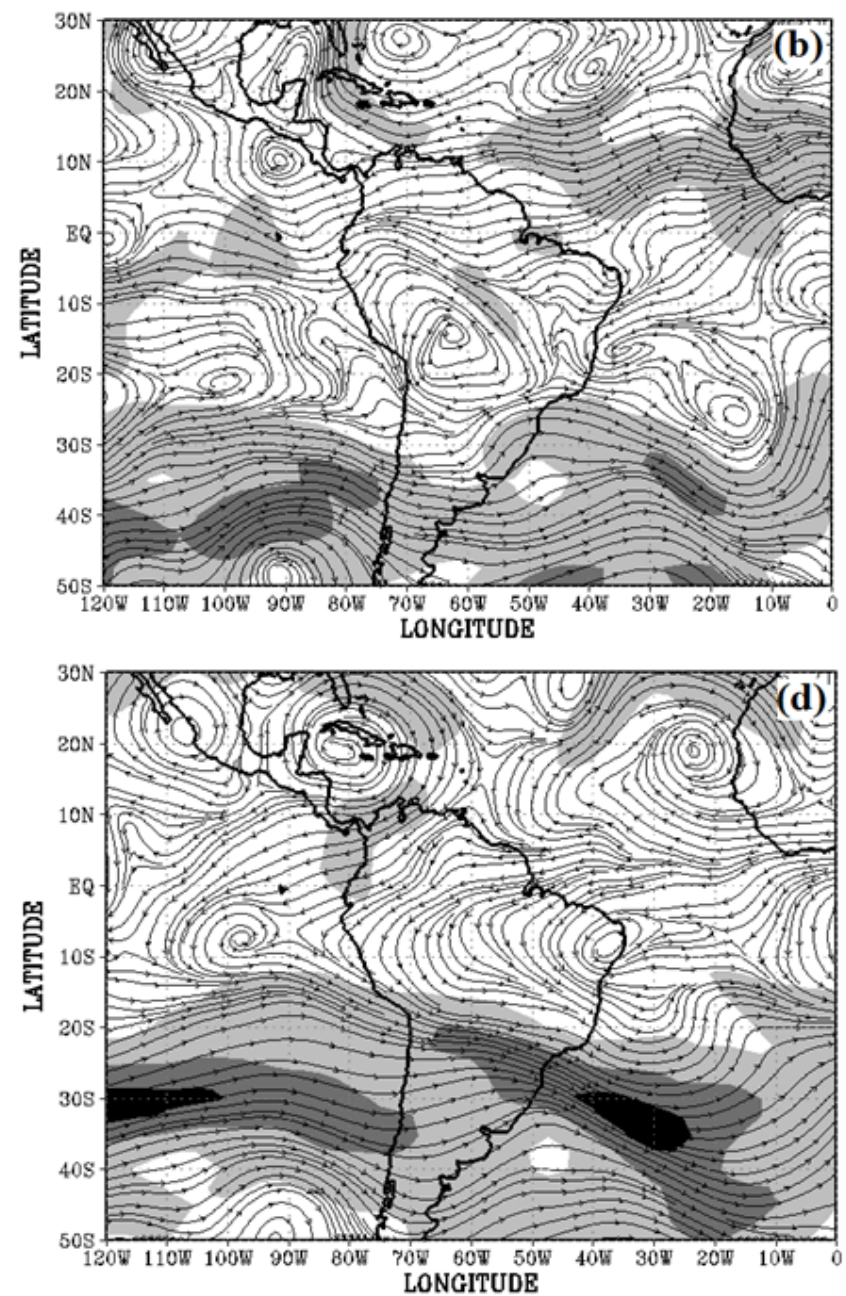

Figura 8 - Análise de linhas de corrente e intensidade do vento para as 0000 UTC do dia 12 de junho de 2006 nos níveis de: (a) 850 hPa, (b) 700 $\mathrm{hPa}$, (c) $500 \mathrm{hPa}$ e (d) $200 \mathrm{hPa}$. A intensidade do vento está representada por: cinza escuro para $60 \mathrm{~m} \mathrm{~s}^{-1} \leq \mathrm{V}\left(30 \mathrm{~m} \mathrm{~s}{ }^{-1} \leq \mathrm{V}\right)$ em $200 \mathrm{hPa}(500 \mathrm{hPa})$, cinza médio para $40 \mathrm{~m} \mathrm{~s}^{-1} \leq \mathrm{V}<60 \mathrm{~m} \mathrm{~s}^{-1}\left(20 \mathrm{~m} \mathrm{~s}^{-1} \leq \mathrm{V}<30 \mathrm{~m} \mathrm{~s}^{-1}\right)$ em $200 \mathrm{hPa}(500,700$ e $850 \mathrm{hPa})$, e cinza claro para $20 \mathrm{~m} \mathrm{~s}^{-1} \leq \mathrm{V}<40 \mathrm{~m} \mathrm{~s}^{-1}(10$ $\left.\mathrm{m} \mathrm{s}^{-1} \leq \mathrm{V}<20 \mathrm{~m} \mathrm{~s}^{-1}\right)$ em $200 \mathrm{hPa}(500,700$ e $850 \mathrm{hPa})$. 

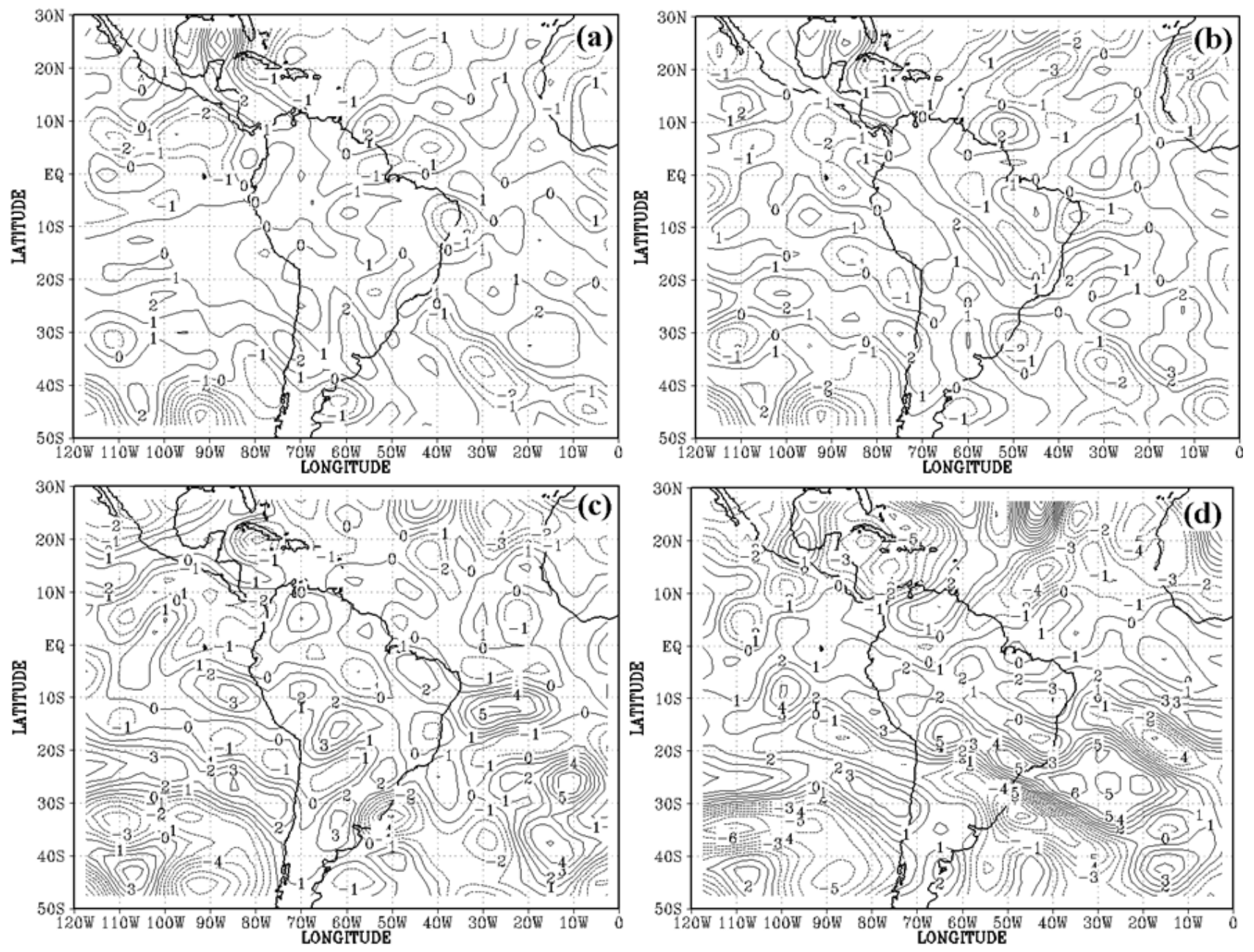

Figura 9 - Componente vertical da vorticidade relativa para as 0000 UTC do dia 12 de junho de 2006 no nível de: (a) 850 hPa, (b) 700 hPa, (c) $500 \mathrm{hPa}$ e (d) $200 \mathrm{hPa}$. O intervalo de análise é de 1,0x10 $10^{-5} \mathrm{~s}^{-1}$. As linhas contínuas (pontilhadas) correspondem a valores positivos (negativos).

centrado na baixa-média troposfera, às 0600 UTC (Figura 10b), horário em que cessa a chuva forte na estação do INEMA(Figura 2). Às 1200 UTC, o núcleo ascendente se estende por toda a troposfera (Figura 10c). A ascendência é mais forte às 1800 UTC (Figura 10d). Essa variação temporal na estrutura vertical do campo do movimento vertical é encontrada em situações de desenvolvimento da convecção. Ascendência com a presença de nuvens cumuliformes profundas e precipitação de moderada a forte também foi diagnosticada em eventos de DOLs no litoral norte do Nordeste (Coutinho e Fish, 2007).

\section{CONCLUSÃO}

Neste trabalho foi analisado o evento de chuva intensa ocorrido no dia 12 de junho de 2006 na área de Salvador, Bahia, com o objetivo de caracterizar as condições atmosféricas e os impactos causados na cidade. No dia anterior ao evento foram observados ventos fracos em toda a troposfera, enquanto que a estrutura termodinâmica mostrava uma atmosfera condicionalmente instável e energia potencial convectiva disponível máxima de $3.233 \mathrm{~J} \mathrm{~kg}^{-1}$, uma condição muito favorável ao desenvolvimento de convecção na região de Salvador. Um total de $51 \mathrm{~mm}$ de precipitação foi registrado pela estação automática do INEMA, entre a meia noite e três horas da madrugada do dia 12. Na estação climatológica principal do INMET o total diário foi de $95 \mathrm{~mm}$, valor que representa $40 \%$ da normal climatológica do mês de junho. A chuva forte foi causada por convecção profunda organizada, cujo desenvolvimento foi favorecido por um distúrbio ondulatório de leste que atingiu a costa leste do Nordeste. A propagação desse sistema, com velocidade de fase estimada em $10 \mathrm{~m} \mathrm{~s}^{-1}$, foi detectada no campo da componente meridional do vento no nível de $700 \mathrm{hPa}$ e em imagens de satélite meteorológico. Deslizamentos de encosta e suas consequências foram os principais danos causados por esse evento extremo de chuva. 

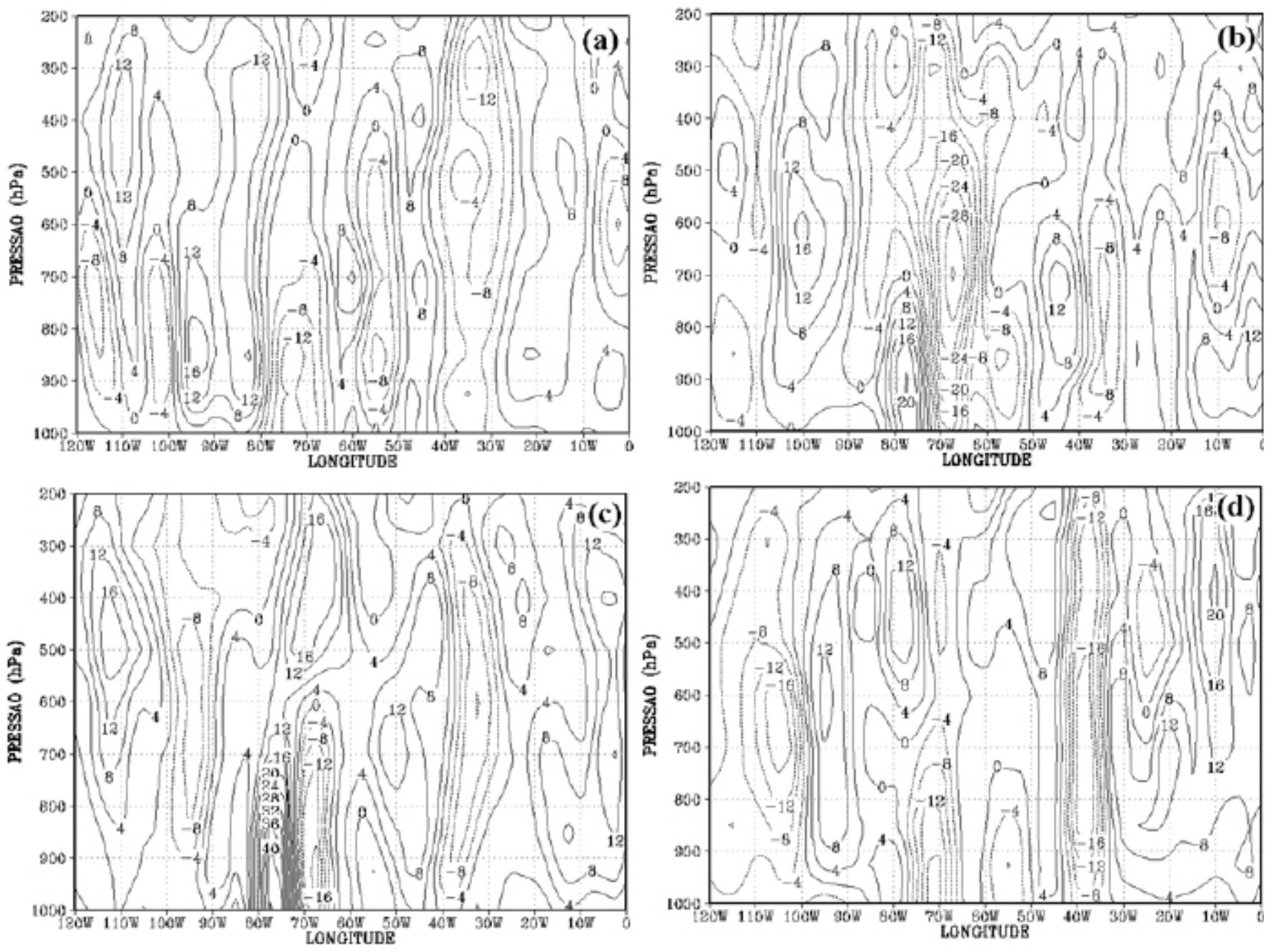

Figura 10 - Seção reta vertical do movimento vertical ao longo da latitude de $13^{\circ} \mathrm{S}$ no dia 12 de junho de 2006 no horário de: (a) 0000 UTC, (b) 0600 UTC, (c) 1200 UTC e (d) 1800 UTC. O intervalo de análise é de 4 x10 $0^{-2} \mathrm{hPa} \mathrm{s}^{-1}$. As linhas contínuas (pontilhadas) correspondem a movimento vertical descendente (ascendente).

\section{AGRADECIMENTOS}

Aos dois revisores pelas críticas e sugestões apresentadas. Ao Instituto Nacional de Meteorologia (INMET) e ao Instituto do Meio Ambiente e Recursos Hídricos (INEMA) pela cessão de dados pluviométricos. À Defesa Civil de Salvador (CODESAL) pela cessão dos registros de ocorrências. Ao Conselho Nacional de Desenvolvimento Científico e Tecnológico (CNPq) pela bolsa de estudos concedida ao primeiro e ao quinto autores.

\section{REFERÊNCIAS BIBLIOGRÁFICAS}

BARRETO, A. B.; SILVA ARAGÃO, M. R., CORREIA, M. F., SANTOS, A. H. M. Uma investigação sobre eventos de chuva intensa na cidade de Salvador, Bahia. In: CONGRESSO BRASILEIRO DE METEOROLOGIA, 15., 2008, São Paulo. Anais... São Paulo: SBMET, 2008. 1 CD-ROM.
BERRY, F. A.; BOLLAY, E.; BEERS, N. R. Handbook of Meteorology. New York: McGraw-Hill Book, 1945, $1068 \mathrm{p}$.

BLUESTEIN, H. B. Synoptic Dynamic Meteorology in Midlatitudes. v. 2 Observations and Theory of Weather Systems. New York: Oxford University Press, 1993, p. 426-455. BOLTON, D. The computation of equivalent potential temperature. Monthly Weather Review, v. 108, p. 10461053, 1980.

CONTI, J. B. Clima e meio ambiente. 6. ed., São Paulo: Saraiva, 1998.

CORREIA, M. F. Diagnóstico via radar dos sistemas precipitantes do semi-árido brasileiro: $O$ evento de 1985. 1989. Dissertação (Mestrado em Meteorologia) Universidade de São Paulo, São Paulo, 1989.

COUTINHO, E. C.; FISH, G. Distúrbios ondulatórios de leste (DOLs) na região do centro de lançamento de Alcântara - 
MA. Revista Brasileira de Meteorologia, v. 22, n. 2, p. 193-203, 2007.

CODESAL - Defesa Civil de Salvador. Operação Chuva 2006: relatório final. Salvador, 2006. 47 p. (Acesso em: 17 de novembro de 2007 no endereço eletrônico $<$ http://www. defesacivil.salvador.ba.br $>$ )

DOMINGUES, M. O.; MENDES JR, O.; CHAN, C. S.; SÁ, L. D. A.; MANZI, A. O. Análise das condições atmosféricas durante a segunda Campanha do Experimento Interdisciplinar do Pantanal Sul Mato-Grossense. Revista Brasileira de Meteorologia, v. 19, n. 1, p. 73-88, 2004.

HALL, B. A. Westward-moving disturbances in the South Atlantic coinciding with heavy rainfall events at Ascension Island. Meteorological Magazine, v. 118, n. 1405, p. 175181, Aug. 1989.

HASTENRATH, S. Climate and circulation of the tropics. New York Atmospheric Sciences Library, 1988.

LAURENT, H.; VILTARD, A.; DE FELICE, P. Performance evolution and local adaptation of the ECMWF system forecast over northern Africa for summer 1985. Monthly Weather Review, v. 117, p. 199-2009, 1989.

LIMA, M. C. Variabilidade da precipitação no litoral leste da região Nordeste do Brasil. 1991. 222 f. Dissertação (Mestrado em Meteorologia) - Instituto Nacional de Pesquisas Espaciais, São José dos Campos, 1991.
MAGALHÃES, A. R. et al. The climatology of droughts and drought prediction. In:_The effects of climatic variations on agriculture in Northeast Brazil. Luxemburg, International Institute for Applied Systems Analysis, 1987.

MOTA, G. V. Estudo observacional de distúrbios ondulatórios de leste no nordeste brasileiro. 1997. 95 f. Dissertação (Mestrado em Meteorologia) - Universidade de São Paulo, São Paulo, 1997.

PAIVANETO, A. C. Distúrbios de leste: Diagnóstico e relação com a precipitação no estado da Paraíba em períodos de contraste. 2003. 107 f. Dissertação (Mestrado em Meteorologia) - Universidade Federal de Campina Grande, Campina Grande, 2003.

RAMOS, A. M.; SANTOS, L. A. R.; FORTES, L. T. G. Normais Climatológicas do Brasil 1961-1990. Brasília, DF: INMET, 2009.

SANTOS, A. H. M. Eventos extremos de chuva em Salvador, Bahia: Condições atmosféricas e impactos ambientais. 2008. 65 f. Dissertação (Mestrado em Meteorologia) Universidade Federal de Campina Grande, Campina Grande, 2008. 